\title{
$(-)-\alpha$-Bisabolol inhibits preferentially electromechanical coupling on rat isolated arteries
}

\author{
R.J.B. de Siqueira *, H.V. Ribeiro-Filho, R.S. Freire, F. Cosker, W.B.S. Freire, A.A. Vasconcelos-Silva, M.A. Soares, \\ S. Lahlou, P.J.C. Magalhães
}

Department of Physiology and Pharmacology, School of Medicine, Federal University of Ceará, Fortaleza, CE, Brazil

\section{A R T I C L E I N F O}

\section{Article history:}

Received 24 March 2014

Received in revised form 9 June 2014

Accepted 26 June 2014

Available online 14 August 2014

\section{Keywords:}

(-)- $\alpha$-Bisabolol

Docking analysis

Electromechanical coupling

Intracellular calcium

Vascular smooth muscle

\begin{abstract}
A B S T R A C T
Previous findings enable us to hypothesize that $(-)$ - $\alpha$-bisabolol acts as inhibitor of voltage-dependent $\mathrm{Ca}^{2+}$ channels in smooth muscle. The current study was aimed at consolidating such hypothesis through the recording of isometric tension, measurement of intracellular $\mathrm{Ca}^{2+}$ as well as discovery of channel target using in silico analysis. In rat aortic rings, $(-)-\alpha$-bisabolol $(1-1000 \mu \mathrm{M})$ relaxed $\mathrm{KCl}$ - and phenylephrine-elicited contractions, but the $\mathrm{IC}_{50}$ differed significantly (22.8 [17.6-27.7] and 200.7 [120.4-334.6] $\mu \mathrm{M}$, respectively). The relaxation of phenylephrine contractions remained unaffected by L-NAME, indomethacin, 1H-[1,2,4]oxadiazolo[4,3-a] quinoxalin-1-one, tetraethylammonium, glibenclamide or KT-5720. Under $\mathrm{Ca}^{2+}$-free conditions, ( -$)$ - $\alpha-$ bisabolol did not alter the contractions evoked by phenylephrine or caffeine whereas it reduced those evoked by $\mathrm{CaCl} 2$ in $\mathrm{KCl}-$, but not in PHE-stimulated preparations. Furthermore, it did not significantly alter the contractions evoked by phorbol 12,13-dibutyrate or induced by the extracellular $\mathrm{Ca}^{2+}$ restoration in cyclopiazonic acidtreated preparations. In mesenteric rings loaded with Fluo-4 AM, $(-)-\alpha$-bisabolol blunted the tension and the cytosolic levels of $\mathrm{Ca}^{2+}$ in response to $\mathrm{K}^{+}$but not to norepinephrine. Silico docking analysis of the Cav 32 a subunit of voltage-dependent $\mathrm{Ca}^{2+}$ channel indicated putative docking sites for $(-)$ - $\alpha$-bisabolol. These findings reinforce the ability of $(-)-\alpha$-bisabolol to inhibit preferentially contractile responses evoked by $\mathrm{Ca}^{2+}$ influx through voltage-dependent $\mathrm{Ca}^{2+}$ channels.
\end{abstract}

(C) 2014 Elsevier Inc. All rights reserved.

\section{Introduction}

(-)- $\alpha$-Bisabolol, also known as levomenol, is a sesquiterpenic monocyclic alcohol abundantly found as the major constituent of the essential oil of chamomile (Matricaria chamomilla L., Asteraceae). It has been attributed to this compound the healing attributes of chamomile, the feature that argues for the use of $(-)$ - $\alpha$-bisabolol in pharmaceutical formulations in virtue of its anti-inflammatory and antiallergic properties [10]. In fact, it has been reported that $(-)-\alpha$-bisabolol has protective effects against gastric damage caused by acetylsalicylic acid [12, $26]$. The antitumor activity of $(-)-\alpha$-bisabolol, which is mediated by its proapoptotic effects, has also recently received special attention in the literature [2-4].

\footnotetext{
* Corresponding author at: Department of Physiology and Pharmacology, School of Medicine, Federal University of Ceará, R. Cel Nunes de Melo, 1127, Rodolfo Teófilo, 60430-270 Fortaleza, CE, Brazil. Tel.: +55 853366 8334; fax: + 558533668333.

E-mail address: rodrigo_siqueira@yahoo.com.br (R.J.B. de Siqueira).
}

In the cardiovascular system, intravenous injections of increasing doses of $(-)$ - $\alpha$-bisabolol induced dose-dependent hypotension and bradycardia in awake rats [13]. However, the mechanism of action of these cardiovascular effects has not been addressed. The hypotensive response to (-)- $\alpha$-bisabolol could be mediated, at least partially, through an active vascular relaxation. We recently found that $(-)-\alpha$-bisabolol induced endothelium-independent relaxation with a pharmacological potency that was higher in mesenteric than in aortic rings [5]. In only aortic rings, $(-)$ - $\alpha$-bisabolol relaxed $\mathrm{KCl}$ induced contractions with pharmacological potency significantly higher than that observed in vessels contracted with phenylephrine. This data indicates that $(-)-\alpha$-bisabolol counteracts contractile responses that preferentially recruit voltage-gated $\mathrm{Ca}^{2+}$ channels, similar to what was reported for tracheal smooth muscle preparations [5].

Putative $\mathrm{Ca}^{2+}$ channel blocking activity as the underlying mechanism for vasodilator action induced by $(-)$ - $\alpha$-bisabolol was previously demonstrated by Vuorela et al. [28]. Such activity has been also reported for bisabolol oxide and $(+)$-T-cadinol, two analogues of $(-)$ - $\alpha$-bisabolol, in experiments with isolated papillary muscle from guinea-pig hearts [16] and binding assays with dihydropyridine on the voltage-operated $\mathrm{Ca}^{2+}$ channels [30]. However, direct demonstration that $(-)$ - $\alpha$-bisabolol is able to interfere with 
cytoplasmic $\mathrm{Ca}^{2+}$ dynamics was not demonstrated in smooth muscle cells hitherto.

Therefore, the present study was designed to test the hypothesis that pharmacological effects of $(-)$ - $\alpha$-bisabolol on vascular smooth muscle result from its ability to interfere with the intracellular levels of $\mathrm{Ca}^{2+}$, especially on those events mediated electromechanically. Docking experiments and simultaneous measurement of mechanical force and $\left[\mathrm{Ca}^{2+}\right]_{i}$ in Fluo-4 loaded mesenteric artery rings stimulated with either $\mathrm{KCl}$ or norepinephrine were performed to support the underlying mechanism involved in the vasorelaxant effects of $(-)$ - $\alpha$-bisabolol.

\section{Materials and methods}

\subsection{Animals}

Male Wistar rats (250-300 g) were obtained from our local colonies (vivarium of the Department of Physiology and Pharmacology, Federal University of Ceará) and maintained under constant temperature $\left(22 \pm 2{ }^{\circ} \mathrm{C}\right)$ with a $12 \mathrm{~h}$ light/ $12 \mathrm{~h}$ dark cycle and free access to food and water. All animals were cared for in compliance with the Guide for the Care and Use of Laboratory Animals, published by the US National Institutes of Health (NIH Publication 85-23, revised 1996). All procedures described herein were reviewed by and had prior approval from the local animal ethics committee (Protocol $n^{\circ} 48 / 09-$ CEPA).

\subsection{Isolated ring-like aortic preparations}

Rats were euthanized under sodium pentobarbital anesthesia and a segment of thoracic aorta was removed and immersed in perfusion medium at room temperature. After removing adhering fat and connective tissue, the aorta was cut transversally into cylindrical ring-like segments $(1 \times 5 \mathrm{~mm})$ receiving careful transluminal insertion of steel wire triangular pieces ( $0.3 \mathrm{~mm}$ diameter) that allowed tissue suspension into 5$\mathrm{mL}$ organ bath containing Krebs-Henseleit solution (continuously aerated at $37{ }^{\circ} \mathrm{C}$ with $5 \% \mathrm{CO}_{2}$ in $\mathrm{O}_{2}$ ). Endothelium-containing preparations were stretched with a passive tension of $1 \mathrm{~g}$ and tension was recorded using isometric force transducer (ML870B60/C-V, AD Instruments, Australia) connected to a data acquisition system (PowerLab ${ }^{\text {TM }} 8 / 30$, AD Instruments). After an equilibration period of $60 \mathrm{~min}$, control contractions were induced by adding a submaximal concentration (60 mM) of $\mathrm{KCl}$ to the bath. When two successive contractions showed similar amplitude, preparations were considered in equilibrium. At the beginning of the experiment, each aortic or mesenteric ring was precontracted with phenylephrine $(0.1 \mu \mathrm{M})$ and thereafter challenged by acetylcholine $(1 \mu \mathrm{M})$ to evaluate the integrity of endothelium. Preparations were considered to possess an intact endothelium when the vasorelaxant response to acetylcholine was $80 \%$ or greater. The concentration-effect curves were obtained by exposing the aortic preparation to cumulatively increasing concentrations of $(-)$-a-bisabolol (1-1000 $\mu \mathrm{mol} / \mathrm{L})$, which was added to the bath and maintained at a given concentration for $10 \mathrm{~min}$.

\subsection{Simultaneous measurement of force and intracellular $\mathrm{Ca}^{2+}$ in rings of mesenteric artery}

Vessel segments from the second branch of the superior mesenteric artery were dissected and maintained in oxygenated Krebs-Henseleit solution at room temperature. After removing adhering fat under a microscope, cylindrical ring-like segments were obtained and carefully mounted in a confocal myograph chamber (DMT120CW Confocal Wire Myograph, Aarhus, Denmark) following the transluminal insertion of two tungsten wires ( $40 \mu \mathrm{m}$ diameter). Then, under constant temperature $\left(37^{\circ} \mathrm{C}\right)$, a resting tension of $11.8 \mathrm{kPa}$ was applied to each isolated artery segment. The preparation was incubated by $50 \mathrm{~min}$ with the fluorescent $\mathrm{Ca}^{2+}$ indicator Fluo-4 AM $(5 \mu \mathrm{M})$ supplemented with pluronic acid $(0.1 \% \mathrm{w} / \mathrm{v})$ (Life Technologies, USA). After washing, the $\mathrm{Ca}^{2+}$ fluorescence was registered with an inverted confocal microscope (Olympus, IX81) using a $20 \times$ magnification and excitation/emission wavelengths of 488/505-515 nm. Sample rate was 1 frame/7 s and the intracellular $\mathrm{Ca}^{2+}$ variations were expressed in relative variation of the initial fluorescence $\left(F / F_{0}\right)$. Simultaneously, the variations of the tension were recorded with an isometric force transducer connected to a data acquisition system (PowerLab ${ }^{\mathrm{TM}} 8 / 30$, AD Instruments).

\subsection{In silico docking analysis}

We employed AutoDock 4.2 [14] in docking experiments using three-dimensional molecular structure of the ligand $(-)-\alpha$-bisabolol (constructed by the molecular editor Avogadro 1.1.0; [6]) in pharmacophoric alignments with macromolecules based on two crystallographic models of a $\beta$-subunit isoform of voltage-gated L-type $\mathrm{Ca}^{2+}$ channel, the conserved core $\mathrm{Ca}_{\mathrm{v}} \beta_{2 \mathrm{a}}$ alone or in complex with the $\alpha$-interaction domain (AID), namely AID- $\mathrm{Ca}_{\mathrm{v}} \beta_{2 \mathrm{a}}$ [27]. The macromolecules and ligand were prepared using the graphical interface AutoDockTools 1.5.6, which allowed the addition of polar hydrogens (Kollman) and partial charges (Gasteiger). For ligand, the number of active torsions was 5 , and both macromolecules were considered rigid. Autogrid (part of the AutoDock package) allowed the construction of affinity grid fields, previously to the docking procedure. For all docking experiments, we used the genetic algorithm available in the software. In a first step of docking experiments, we constructed a $0.59 \AA$ A-spaced grid field that covered the entire macromolecule of either $\mathrm{Ca}_{\mathrm{v}} \beta_{2 \mathrm{a}}$ or AID- $\mathrm{Ca}_{\mathrm{v}} \beta_{2 \mathrm{a}}$. The numbers of energy evaluations and docking runs were $2,500,000$ and 50, respectively, and other parameters were maintained as default. According to the results of the first step, a second series of simulations was performed by constructing two grid fields (with points spaced by $0.38 \AA$ ), one centered on the Hook domain (residues 121-169) and the other centered near to the conserved hydrophobic cleft named $\alpha$-binding pocket. Such region engages $\mathrm{Ca}_{\mathrm{v}} \beta_{2 \mathrm{a}}$ with AID. The parameters were maintained as previously described. The cluster populations and binding energy as well as proximity of the residues were taken into account in the docking analysis.

\subsection{Solutions and drugs}

The perfusion medium used in isolated organ chamber was fresh modified Krebs-Henseleit solution ( $\mathrm{pH} 7.4$; in mM: $118.0 \mathrm{NaCl}, 4.7$ $\mathrm{KCl}, 1.18 \mathrm{KH}_{2} \mathrm{PO}_{4}, 1.18 \mathrm{MgSO}_{4} \cdot 7 \mathrm{H}_{2} \mathrm{O}, 2.50 \mathrm{CaCl}_{2}, 25.0 \mathrm{NaHCO}_{3}$, and 11.1 glucose). Nominally $\mathrm{Ca}^{2+}$-free solution was prepared by omitting $\mathrm{CaCl}_{2}$ and adding ethylene glycol bis(2-aminoethyl ether)-N,N, $\mathrm{N}^{\prime} \mathrm{N}^{\prime}$-tetraacetic acid (EGTA). All drugs were of analytical grade purity purchased from Sigma Co. (St. Louis, MO, USA). They were dissolved directly in Krebs-Henseleit solution except nifedipine, cyclopiazonic acid, KT-5720 and 1H-[1,2,4]oxadiazolo[4,3-a] quinoxalin-1-one (ODQ) that were dissolved directly in DMSO (dimethyl sulfoxide). Solutions of $(-)$ - $\alpha$-bisabolol (bisabolol; SigmaAldrich) were prepared in Krebs-Henseleit solution containing Tween 80 (0.5\%). Maximal percentage of Tween 80 in bath chamber was $0.06 \%$. Substances were prepared as stock solutions and were brought to volume with Krebs-Henseleit solution in order to achieve a desired concentration in bath chamber.

\subsection{Statistical analysis}

Data are reported as mean \pm SEM and $n$ indicates the number of experiments. The $\mathrm{IC}_{50}$ values (i.e., the $(-)$ - $\alpha$-bisabolol concentration in $\mu \mathrm{M}$ that relaxes a contraction by $50 \%$ ) were calculated by interpolation from semi-logarithmic plots and are expressed as geometric mean [95\% confidence interval]. The significance $(p<0.05)$ of results was assessed using paired or unpaired Student's t-test, Mann-Whitney U- 
test, and one- or two-way analysis of variance (ANOVA) followed by the Holm-Sidak post hoc test when appropriate.

\section{Results}

3.1. Vasodilator effects of (-)- $\alpha$-bisabolol in aortic rings contracted with high $\mathrm{KCl}$ or phenylephrine

Aortic rings produced sustained contractions corresponding to $1.52 \pm 0.15(\mathrm{n}=6)$ and $1.30 \pm 0.11 \mathrm{~g}(\mathrm{n}=7)$ in response to $1 \mu \mathrm{M}$ phenylephrine and $60 \mathrm{mM} \mathrm{KCl}$ (Fig. 1A). The cumulative addition of $(-)$ - $\alpha$-bisabolol $(1-1000 \mu \mathrm{M})$ fully relaxed the phenylephrineand $\mathrm{KCl}$-induced contractions with $\mathrm{IC}_{50}$ values of 200.7 [120.4334.6] and 22.8 [17.6-27.7] $\mu \mathrm{M}$, respectively. However, the potency of $(-)$ - $\alpha$-bisabolol in inducing relaxant effect was significantly ( $p<0.05$, Mann-Whitney U-test) higher in preparations contracted by $\mathrm{KCl}$. The cumulative addition of vehicle (Tween 80 ) does not exert significant effect on preparations precontracted with $\mathrm{KCl}$ $60 \mathrm{mM}$ (Fig. 1A).

In a separate set of tissues contracted with phenylephrine $(1 \mu \mathrm{M})$, pretreatment with L-NAME $(100 \mu \mathrm{M})$, ODQ $(10 \mu \mathrm{M})$ or indomethacin (INDO, $10 \mu \mathrm{M})$ (Fig. 1B) as well as with TEA (1 mM), glibenclamide $(10 \mu \mathrm{M})$ or KT-5720 $(10 \mu \mathrm{M})$ (Fig. 1C) did not change the vasodilator effect of $(-)$ - $\alpha$-bisabolol as none of these pretreatments altered the $\mathrm{IC}_{50}$ value of $(-)$ - $\alpha$-bisabolol-induced vasorelaxation (Table $1 ; p>0.05$, Mann-Whitney U-test).

3.2. Inhibitory effects of (-)- $\alpha$-bisabolol on the contractions induced by $\mathrm{Ca}^{2+}$ or $\mathrm{Ba}^{2+}$ in preparations maintained in the presence of $\mathrm{KCl}$ or phenylephrine

Considering that the phenylephrine-induced contraction was reduced almost a half $(59.4 \pm 6.1 \%)$ by $100 \mu \mathrm{M}(-)$ - $\alpha$-bisabolol, this concentration was used in all subsequent experiments. Under $\mathrm{Ca}^{2+}$-free conditions (in the presence of $60 \mathrm{mM} \mathrm{KCl}$ and $10 \mu \mathrm{M}$ EGTA), aortic rings contracted promptly in a concentrationdependent manner ( $p<0.001$, ANOVA) when increasing concentrations (0.1-20 mM) of either $\mathrm{Ca}^{2+}$ (Fig. 2A) or $\mathrm{Ba}^{2+}$ (Fig. 2B) were added in the extracellular medium (maximal effect of $163.2 \pm 4.1$ $[n=6]$ and $130.8 \pm 3.4 \%[n=5]$, respectively; values are $\%$ of the reference contraction induced by $60 \mathrm{mM} \mathrm{KCl}$ in $\mathrm{Ca}^{2+}$-containing medium). The maximum contractile effect induced by $\mathrm{Ca}^{2+}$ or $\mathrm{Ba}^{2+}$ was significantly reduced ( $\mathrm{p}<0.05$, two-way ANOVA followed by HolmSidak test $)$ in the presence of $(-)$ - $\alpha$-bisabolol $(100 \mu \mathrm{M})$ to $45.2 \pm 5.7$ (Fig. $2 \mathrm{~A}, \mathrm{n}=6$ ) and $44.4 \pm 10.3 \%$ (Fig. $2 \mathrm{~B}, \mathrm{n}=5$ ), respectively. Interestingly, when phenylephrine $(60 \mu \mathrm{M})$ was the agonist in $\mathrm{Ca}^{2+}$-free medium (containing $10 \mu \mathrm{M}$ EGTA and $1 \mu \mathrm{M}$ nifedipine), contractions due to $\mathrm{Ca}^{2+}(0.1-20 \mathrm{mM})$ addition remained significantly $(\mathrm{p}>0.05$, two-way ANOVA) unaffected by $100 \mu \mathrm{M}(-)$ - $\alpha$-bisabolol (Fig. 2C, $\mathrm{n}=3$ ).

3.3. (-)- $\alpha$-Bisabolol does not interfere with the contractions mediated intracellularly by phenylephrine or caffeine in aortic rings under $\mathrm{Ca}^{2+}{ }_{-}$free conditions

In aortic rings with intact endothelium under $\mathrm{Ca}^{2+}$-free conditions (in the presence of $1 \mathrm{mM} \mathrm{EGTA}$ ), phenylephrine $(1 \mu \mathrm{M})$ induced a transient (phasic) contraction that corresponded to $28.5 \pm 3.4 \%$ $(\mathrm{n}=8)$ of the $\mathrm{K}^{+}$-induced response under nominally normal $\mathrm{Ca}^{2+}$ (Fig. 3A). The previous addition of $(-)$ - $\alpha$-bisabolol $(100 \mu \mathrm{M}, \mathrm{n}=$ 6) did not change ( $p>0.05$, paired Student's t-test) this phasic contraction $(30.4 \pm 4.6 \%)$. In other set of experiments with aortic preparations (with intact endothelium) maintained in $\mathrm{Ca}^{2+}$-free medium at $25^{\circ} \mathrm{C},(-)$ - $\alpha$-bisabolol $(100 \mu \mathrm{M})$ was also ineffective $(\mathrm{p}>0.05$, paired Student's t-test) when caffeine $(30 \mathrm{mM})$ was employed as the contractile agent. In fact, the transient contraction induced by
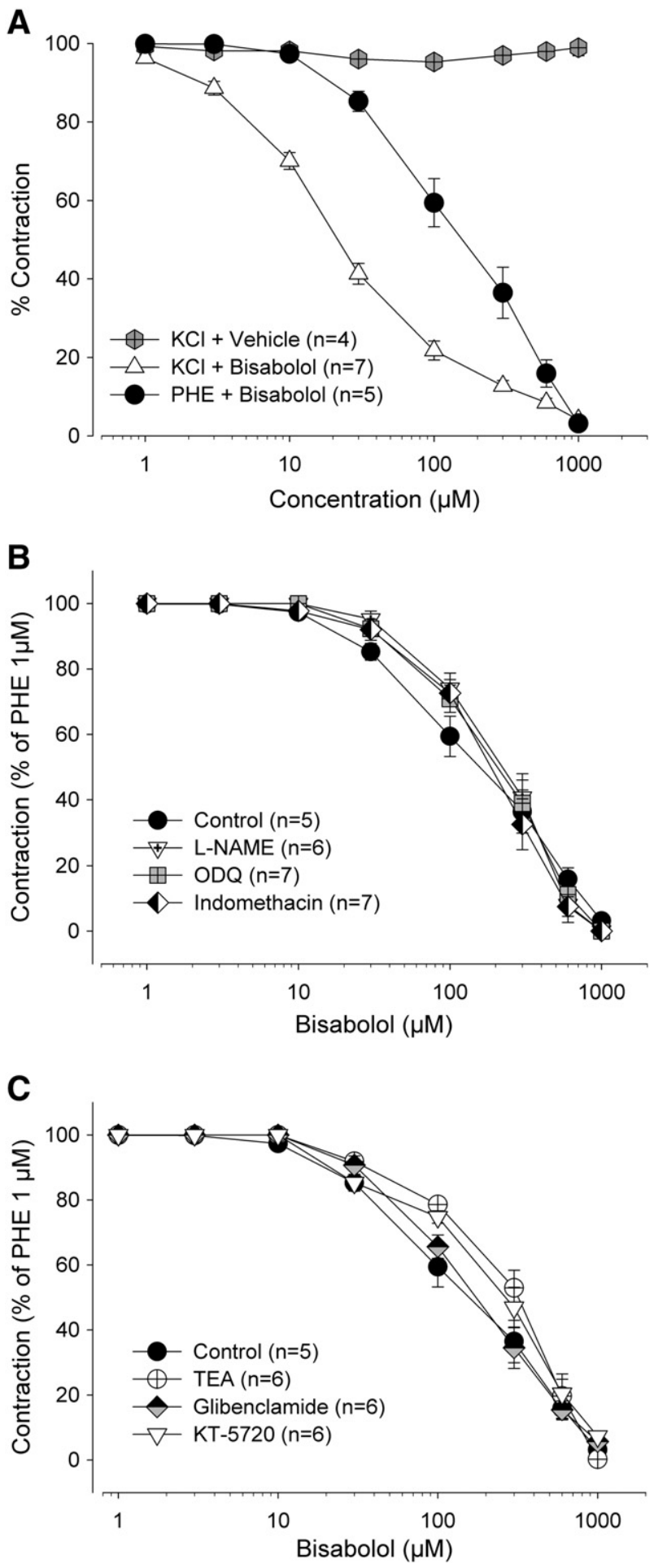

Fig. 1. Effects of (-)- $\alpha$-bisabolol on phenylephrine- or $\mathrm{KCl}$-induced sustained contractions in rat aortic rings. Concentration-response curves were constructed by the addition of bisabolol $(1-1000 \mu \mathrm{M}$ ) or his vehicle (Tween $80 ; 1-1000 \mu \mathrm{M}$ ) on the steady state of induced contractions (panel A). Bisabolol was cumulatively added after phenylephrine $(1 \mu \mathrm{M})$-induced contractions in the absence (control) or in the presence of L-NAME $(100 \mu \mathrm{M})$, indomethacin $(10 \mu \mathrm{M})$, or ODQ $(10 \mu \mathrm{M})$ (panel B) or in the presence of TEA $(1 \mathrm{mM})$, glibenclamide $(10 \mu \mathrm{M})$ or KT-5720 $(10 \mu \mathrm{M})$ (panel $\mathrm{C})$. The results are mean \pm S.E.M. and the number of experiments is indicated as $\mathrm{n}$.

caffeine corresponded to $15.9 \pm 2.0$ and $23.4 \pm 3.7 \%$ of the reference contraction induced by $60 \mathrm{mM} \mathrm{KCl}$ in the absence $(\mathrm{n}=8)$ and in the presence $(n=6)$ of $(-)$ - $\alpha$-bisabolol, respectively (Fig. 3B). 


\section{Table 1}

$\mathrm{IC}_{50}$ values for the relaxing effects induced by $(-)$ - $\alpha$-bisabolol in aortic rings (pretreated or not with L-NAME, indomethacin, ODQ, TEA, glibenclamide or KT-5720) that were pre-contracted with $1 \mu \mathrm{M}$ phenylephrine or $60 \mathrm{mM} \mathrm{KCl}$. Values are geometric mean [95\% confidence interval].

\begin{tabular}{lc}
\hline Treatment & $\mathrm{IC}_{50}(\mu \mathrm{M})$ \\
\hline Phenylephrine & $200.7[120.4-334.6]$ \\
+ L-NAME $(100 \mu \mathrm{M})$ & $213.5[138.6-329.1]$ \\
+ Indomethacin $(10 \mu \mathrm{M})$ & $190.1[130.4-277.1]$ \\
+ ODQ $(10 \mu \mathrm{M})$ & $216.9[141.7-332.1]$ \\
+ TEA $(1 \mathrm{mM})$ & $318.3[210.3-481.8]$ \\
+ Glibenclamide $(10 \mu \mathrm{M})$ & $186.1[114.5-302.4]$ \\
+ KT-5720 $(10 \mu \mathrm{M})$ & $261.2[179.3-380.5]$ \\
$\mathrm{KCl}$ & $22.1[17.6-27.7]^{\mathrm{a}}$ \\
\hline
\end{tabular}

${ }^{\mathrm{a}} \mathrm{p}<0.05$ by Mann-Whitney U-test vs. phenylephrine alone.

3.4. ( -)- $\alpha$-Bisabolol does not interfere with the contractions induced by internal $\mathrm{Ca}^{2+}$ store depletion or by phorbol 12,13-dibutyrate in aortic rings under $\mathrm{Ca}^{2+}$-free conditions

In order to assess the effects of $(-)$ - $\alpha$-bisabolol on contractions induced by $\mathrm{Ca}^{2+}$ influx after internal $\mathrm{Ca}^{2+}$ store depletion, aortic rings were exposed to successive stimuli (3-4 times) induced by phenylephrine $(10 \mu \mathrm{M})$ in $\mathrm{Ca}^{2+}$-free medium containing nifedipine $(1 \mu \mathrm{M})$ and cyclopiazonic acid $(10 \mu \mathrm{M})$ until testifying no measurable contraction in response to phenylephrine. After phenylephrine removal from the extracellular medium, the extracellular $\mathrm{Ca}^{2+}$ was restored to $2 \mathrm{mM}$ still in the presence of nifedipine and cyclopiazonic acid. This procedure allowed aortic rings to produce sustained contractions corresponding to $54.7 \pm 13.0 \%(\mathrm{n}=5)$ of the reference contraction induced by $\mathrm{KCl}(60 \mathrm{mM})$. Pretreatment with $(-)$ - $\alpha$-bisabolol $(100 \mu \mathrm{M})$ did not change significantly $(\mathrm{p}>0.05$, paired Student's ttest) this contraction induced by the $\mathrm{Ca}^{2+}$ restoration $(45.1 \pm 8.5 \%$, $\mathrm{n}=5$ ). In a separate set of experiments, the addition of the protein kinase C (PKC) activator phorbol 12,13-dibutyrate $(1 \mu \mathrm{M})$ to aortic rings with intact endothelium and maintained in $\mathrm{Ca}^{2+}$-free medium (with $1 \mathrm{mM}$ EGTA) produces a sustained contraction corresponding to $171.1 \pm 18.5 \%(n=6)$ of the reference contraction. In the same aortic preparation, the addiction of $(-)-\alpha$-bisabolol $(100 \mu \mathrm{M}, \mathrm{n}=6)$ did not significantly changed ( $p>0.05$, paired Student's t-test) the sustained contraction $(172.0 \pm 19.6 \%$ of the reference contraction).

3.5. Inhibitory effects of (-)- $\alpha$-bisabolol on $\mathrm{K}^{+}$-induced contractions occur simultaneously to a decrease in cytoplasmic $\mathrm{Ca}^{2+}$ levels in mesenteric rings

In Fluo-4 AM-loaded mesenteric vessels stimulated by $\mathrm{KCl}$ (mean amplitude of $3.50 \pm 0.64 \mathrm{mN} ; \mathrm{n}=4),(-)$ - $\alpha$-bisabolol $(100 \mu \mathrm{M}, \mathrm{n}=$ 4) significantly reduced the fluorescence ratio (F/F0) related to the cytoplasmic $\mathrm{Ca}^{2+}$ to $50.7 \pm 5.5 \%$ of the fluorescence observed in control preparations (Fig. 4A, B, C), whereas it significantly reduced the contractile effect of $\mathrm{K}^{+}$to $0.68 \pm 0.10 \mathrm{mN}$ (Fig. 4D) ( $\mathrm{p}<0.05$, paired Student's ttest). In contrast, such reduction induced by $(-)-\alpha$-bisabolol was not seen when mesenteric vessels were stimulated by norepinephrine $(60 \mu \mathrm{M}, \mathrm{n}=4)$. As one can see in Fig. 4 (panels $\mathrm{E}$ to $\mathrm{H}$ ), neither the contractile force (Fig. 4H) nor the cytoplasmic fluorescence (Fig. 4G) was significantly changed by the pretreatment with $100 \mu \mathrm{M}(-)-\alpha-$ bisabolol $(\mathrm{p}>0.05$, paired Student's t-test, $\mathrm{n}=4)$.

3.6. In silico analysis of the molecular interaction between (-)- $\alpha$-bisabolol and $\mathrm{Ca}^{2+}$ channels

The first step of docking experiments indicated two preferential regions in the surface of $\mathrm{Ca}_{\mathrm{v}} \beta_{2 \mathrm{a}}$ subunit (Fig. 5A-C) for (-)- $\alpha$-bisabolol interactions. The first one is located near the $\alpha_{2}$-helix in the HOOK
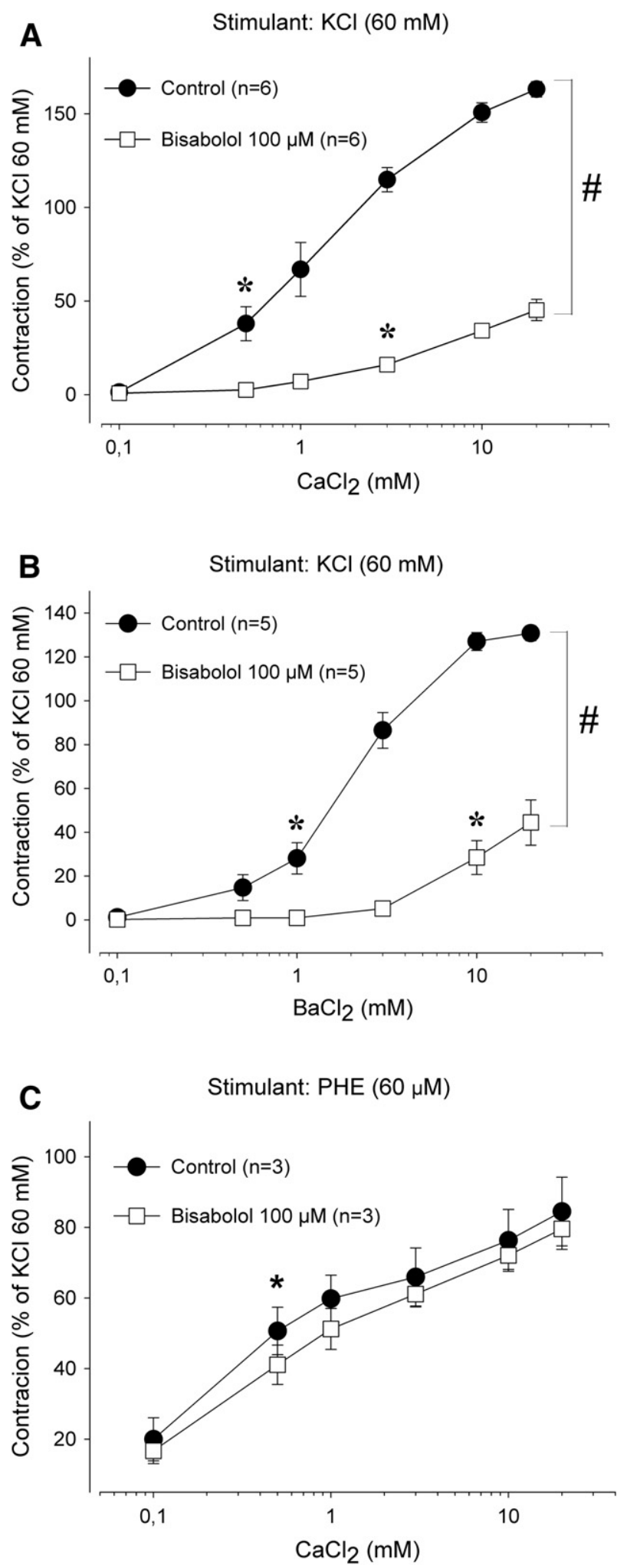

Fig. 2. Effects of (-)- $\alpha$-bisabolol on contractions induced by cumulative addition of $\mathrm{Ca}^{2+}$ or $\mathrm{Ba}^{2+}$ in aortic rings maintained in the presence of $\mathrm{KCl}$ or phenylephrine under $\mathrm{Ca}^{2+}$. free conditions. The cumulative addition of $\mathrm{Ca}^{2+}(0.1$ to $20 \mathrm{mM}$; panels $\mathrm{A}$ and $\mathrm{C})$ or $\mathrm{Ba}^{2+}(0.1$ to $20 \mathrm{mM}$; panel B) contracted aortic rings stimulated with $60 \mathrm{mM} \mathrm{KCl}$ (panels $\mathrm{A}$ and $\mathrm{B}$ ) or $60 \mu \mathrm{M}$ phenylephrine (panel $\mathrm{C}$ ) under $\mathrm{Ca}^{2+}$-free conditions in a concentrationdependent manner (control; $\mathrm{p}<0.001$, one-way ANOVA). Pretreatment with $100 \mu \mathrm{M}$ bisabolol significantly blunted the contractile response to exogenous $\mathrm{Ca}^{2+}$ in $\mathrm{KCl}$ - but not in phenylephrine-stimulated preparations. Results are mean \pm S.E.M. and the number of experiments is indicated as n. ${ }^{*} \mathrm{p}<0.05$, first significant effect by one-way ANOVA followed by Holm-Sidak test; ${ }^{\#} \mathrm{p}<0.05$, two-way ANOVA, $(-)-\alpha$-bisabolol vs. control. 

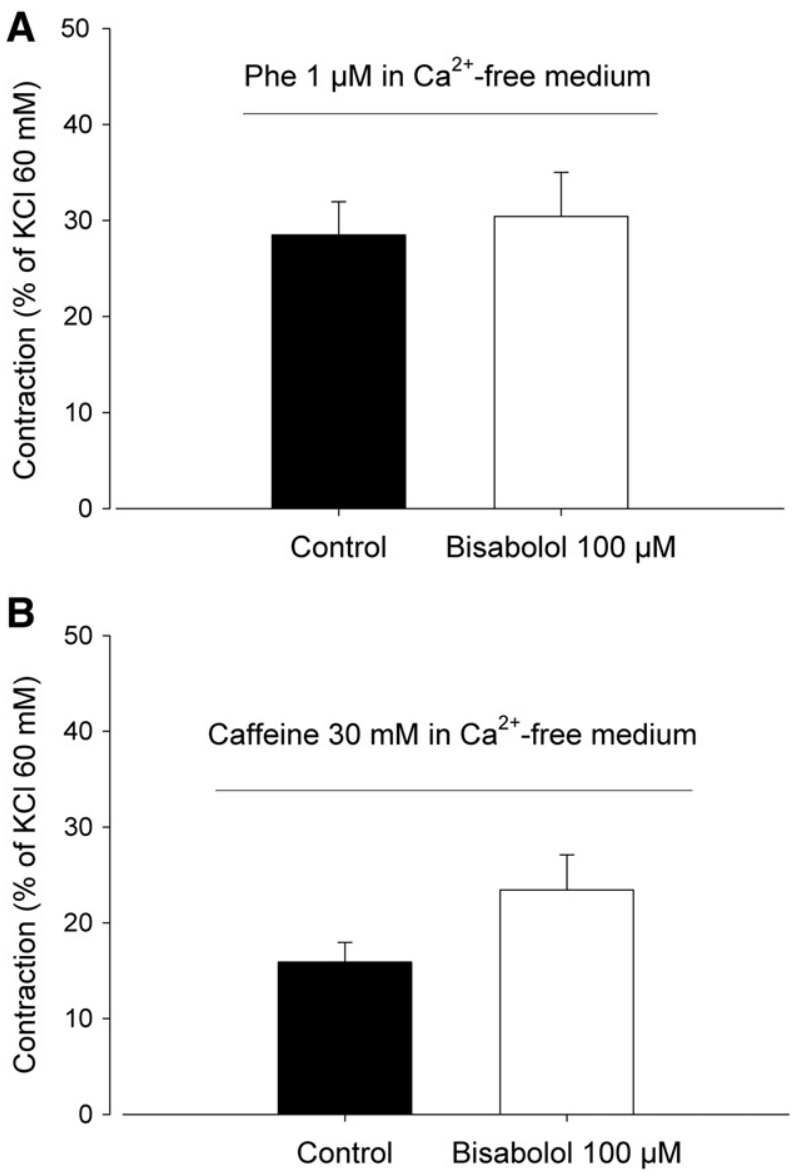

Fig. 3. (-)- $\alpha$-Bisabolol does not interfere with the phasic contractions induced by phenylephrine or caffeine in rat aortic rings under $\mathrm{Ca}^{2+}$-free conditions. Phasic (unsustained) contractions were induced in aortic rings maintained in $\mathrm{Ca}^{2+}$-free medium after stimulus with phenylephrine ( $1 \mu \mathrm{M}$; panel A) or caffeine $(30 \mathrm{mM}$; panel B) and their magnitude was expressed as \% of the reference contraction induced by $60 \mathrm{mM} \mathrm{KCl}$ under $\mathrm{Ca}^{2+}$ containing conditions. Pretreatment with bisabolol $(100 \mu \mathrm{M})$ did not change the magnitude of these contractions ( $\mathrm{p}>0.05$, paired Student's t-test). Results are mean \pm S.E.M. $(\mathrm{n}=6-8$ preparations by group).

domain (Fig. 5A) as it revealed the five biggest population clusters with binding energy lower than $-5 \mathrm{kcal} / \mathrm{mol}$. The other, located near the $\alpha$ binding pocket, presented only two clusters, but with the lowest energy $(-6.11$ and $6.08 \mathrm{kcal} / \mathrm{mol}$; Fig. 5A). When docking experiments were performed with the complex AID- $\mathrm{Ca}_{\mathrm{v}} \beta_{2 \mathrm{a}}$ (Fig. $5 \mathrm{D}-\mathrm{F}$ ) the clusters were distributed only near the HOOK domain with binding energy of $-6.17 \mathrm{kcal} / \mathrm{mol}$ (Fig. 5D).

Second step of analysis centering at the HOOK domain of the $\mathrm{Ca}_{\mathrm{v}} \beta_{2 \mathrm{a}}$ revealed the occurrence of a hydrogen bond between docked $(-)-\alpha-$ bisabolol and LEU84 residue within a distance of $1.976 \AA$ in its best docked conformation $(-6.34 \mathrm{kcal} / \mathrm{mol})$. The closest residues with atoms closer than $4 \AA$ from docked $(-)$ - $\alpha$-bisabolol were VAL28, ARG29, TYR30, SER31, PRO81, LEU84, GLU85, MET87, ARG88, THR101, and PRO103 (Fig. 5B). When the analysis was centered at the $\alpha$ binding pocket region, the lowest binding energy was $-6.88 \mathrm{kcal} / \mathrm{mol}$ to the best docked conformation and two hydrogen bonds (distance of $2.204 \AA$ and $2.182 \AA$ ) were seen between $(-)$ - $\alpha$-bisabolol and ASN258, a residue of in the $\mathrm{Ca}_{\mathrm{v}} \beta_{2 \mathrm{a}} \alpha 8$-helix. The residues with atoms closer than $4 \AA$ from docked (-)- $\alpha$-bisabolol were VAL215, LYS216, ILE217, SER218, SER219, MET129, LEU255, ASP256, GLU257, ASN258, and ALA263 (Fig. 5C). All these residues are part of the $\mathrm{Ca}_{\mathrm{v}} \beta_{2 \mathrm{a}} \alpha$-binding pocket (residues highlighted in blue in Fig. 5D). The results of the second step with AID-Cav $\beta_{2 a}$ subunit revealed a binding energy of
$-6.49 \mathrm{kcal} / \mathrm{mol}$ in the best docked conformation of $(-)$ - $\alpha$-bisabolol near the HOOK domain (Fig. 5E), which established one hydrogen bond with ARG128 residue in the AID-Ca $\mathrm{a}_{2 \mathrm{a}} \alpha 2$-helix (distance of 2.179 Å) (Fig. 5L) and VAL68, ARG69, TYR70, PRO121, LEU124, GLU125, MET127, THR217, and PRO219 and were the residues with atoms closer than $4 \AA$ A from docked (-)- $\alpha$-bisabolol (Fig. 5E).

\section{Discussion}

Previously we showed that in rat tracheal smooth muscle $(-)-\alpha$ bisabolol induced its antispasmodic effects preferentially through inhibition of cellular mechanisms recruiting plasmalemmal voltagedependent $\mathrm{Ca}^{2+}$ influx [5]. The present findings using vascular smooth muscle rat preparations expand this previous work showing that such a mechanism is not peculiar to tracheal smooth muscle. This mode of action for the vasorelaxant effect of $(-)-\alpha$-bisabolol was presently supported by data obtained from simultaneous measurement of force and intracellular $\mathrm{Ca}^{2+}$ in rings of mesenteric artery as well as from in silico docking analysis of the $\mathrm{Ca}_{\mathrm{v}} \beta_{2 \mathrm{a}}$ subunit of voltage-dependent $\mathrm{Ca}^{2+}$ channel.

Putative participation of the vascular endothelium in modulating $(-)$ - $\alpha$-bisabolol-induced relaxation has been previously investigated [5]. Our previous results show that the smooth muscle-relaxing activity of $(-)$ - $\alpha$-bisabolol in aortic preparations is independent of the integrity of endothelial layer as it remained unaltered by vascular endothelium removal [5]. The present study expands this finding showing that the vasorelaxant effects of $(-)$ - $\alpha$-bisabolol are resistant to pretreatment with L-NAME and indomethacin indicating that neither oxide nitric nor prostaglandin release is involved. Furthermore, vasorelaxation of $(-)$ - $\alpha$-bisabolol could not be attributed to a putative ability of this substance in producing $\mathrm{K}^{+}$-channel opening as there was no effect of pharmacological blockade of potassium channels with either glibenclamide or TEA. Finally, neither soluble guanylate cyclase (sGC) nor adenylyl cyclase activation is involved in the mediation of vasorelaxant effects of $(-)-\alpha$-bisabolol as they were unaffected following pre-incubation of aortic preparations with the sGC inhibitor ODQ and the cAMP-dependent protein kinase A inhibitor KT-5720, respectively. These data are consistent with a recent study showing vasodilatory effect of bioactive components from Matricaria recutita L., including the $(-)-\alpha$-bisabolol, in porcine vessels [21].

High $\mathrm{KCl}$ induces membrane depolarization, which, in turn, opens the VOCCs, promotes $\mathrm{Ca}^{2+}$ influx, increases $\left[\mathrm{Ca}^{2+}\right]_{i}$, and elicits sustained contraction following myosin light chain phosphorylation [25]. On the other hand, phenylephrine contracts vascular smooth muscle as result of the $\alpha_{1}$-adrenoceptor causing an initial phase of contraction elicited by $\mathrm{IP}_{3}$-induced intracellular $\mathrm{Ca}^{2+}$ release from sarcoplasmic reticulum, followed by a second sustained phase that develops slowly and depends on dihydropyridine-insensitive $\mathrm{Ca}^{2+}$ influx through receptor-operated channels (ROCCs) [29]. The present study showed that in aortic preparations with intact endothelium, $(-)$ - $\alpha$-bisabolol was able to inhibit $\mathrm{KCl}$-induced contractions with pharmacological potency significantly higher (almost 10 -fold increase) than that observed in the same preparations contracted with phenylephrine. This implies that in aortic preparations $(-)$ - $\alpha$-bisabolol also acts against contractile responses that recruit preferentially voltage-gated $\mathrm{Ca}^{2+}$ channels as was previously reported for the tracheal smooth muscle. Such mode of action of $(-)-\alpha$-bisabolol is further supported by some experiments performed under $\mathrm{Ca}^{2+}$-free conditions. In aortic preparations depolarized with high $\mathrm{KCl}$ maintained under such conditions, the contractions induced by $\mathrm{CaCl}_{2}$, which are due to an increase in $\mathrm{Ca}^{2+}$ influx through VOCCs, were significantly reduced by $(-)$ - $\alpha$-bisabolol. Under the same conditions, (-)- $\alpha$-bisabolol was equally effective against contractile responses to increasing concentrations of $\mathrm{Ba}^{2+}$, an ion that selectively passes through VOCCs but is poorly permeable on ROCCs $[15,23]$. However, in the presence of nifedipine to remove the 
A

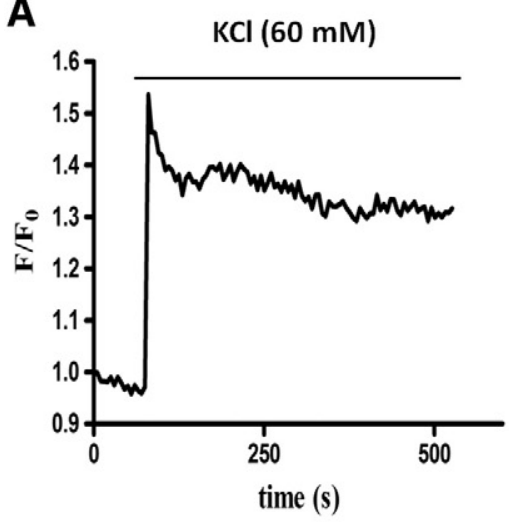

B

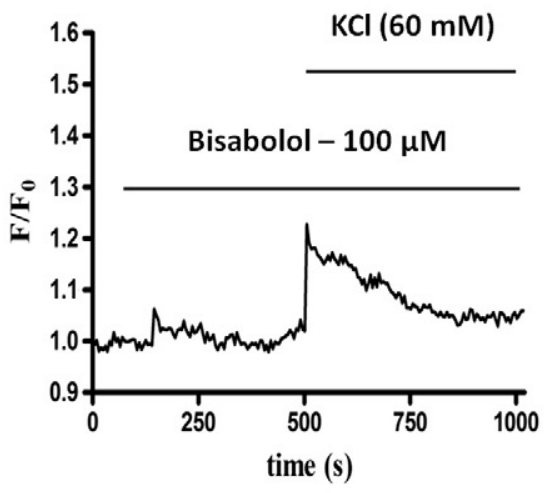

C

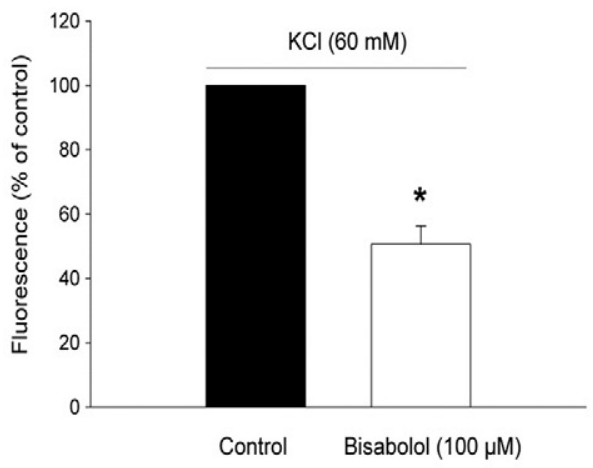

D

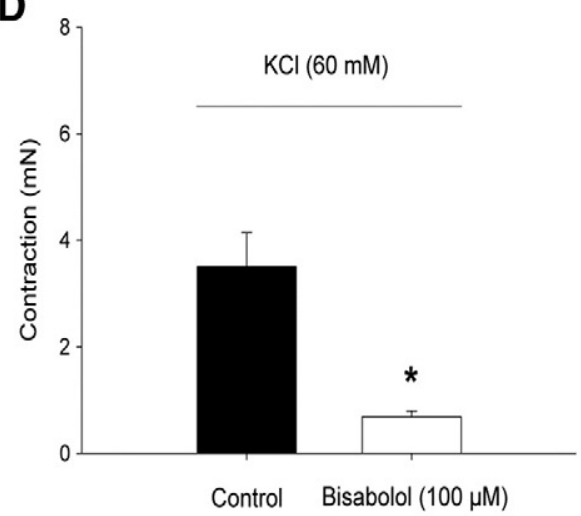

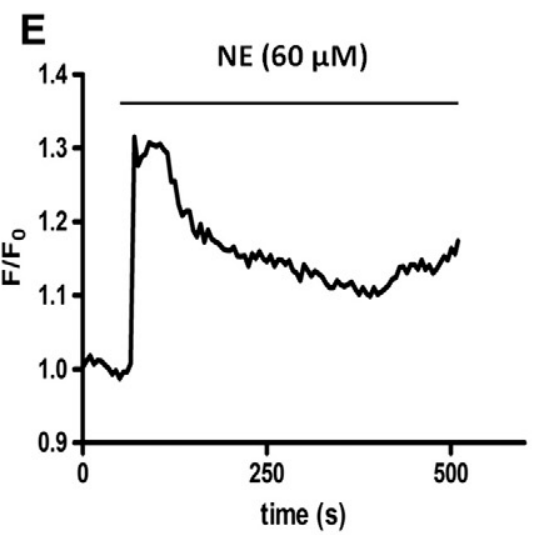

F

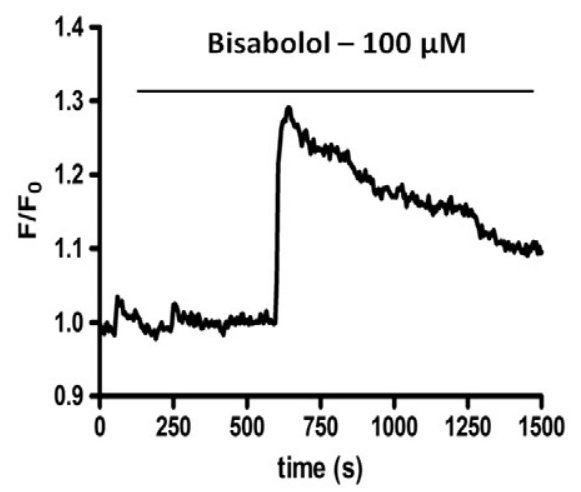

G
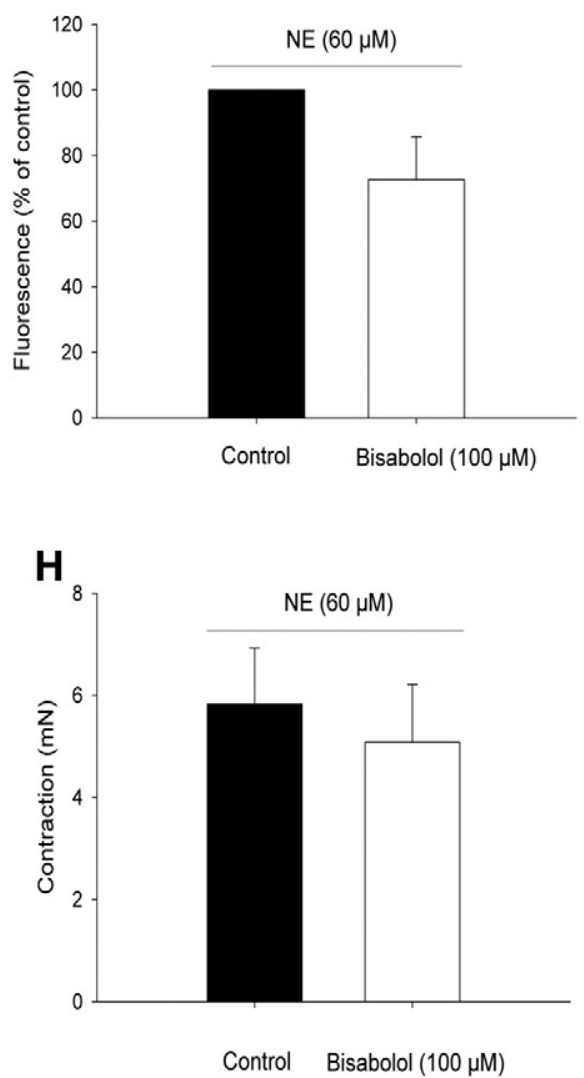
A

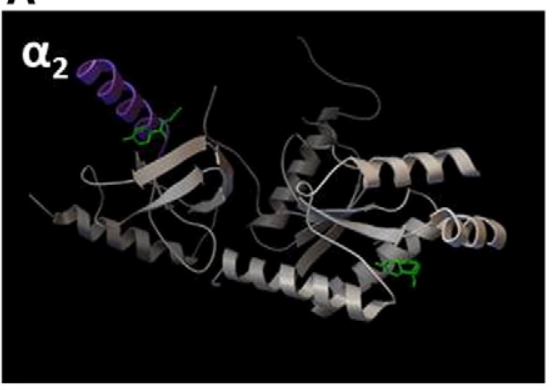

B

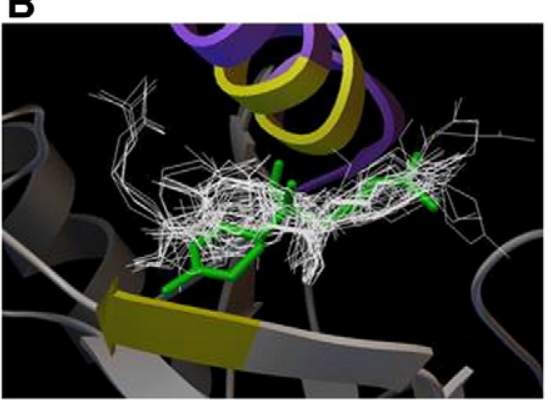

C

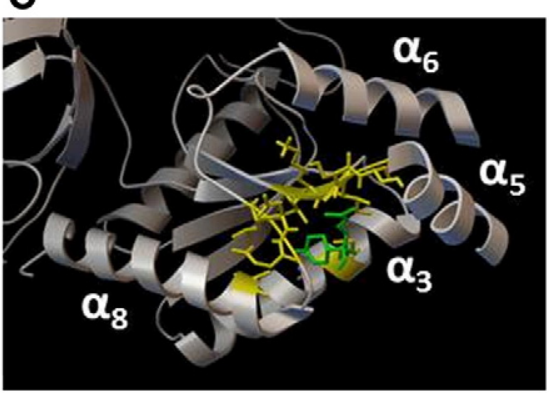

D

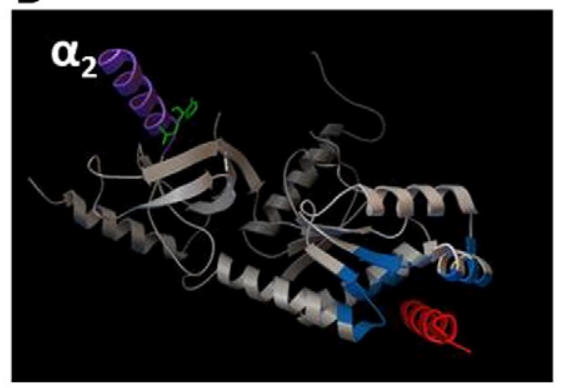

$\mathrm{E}$

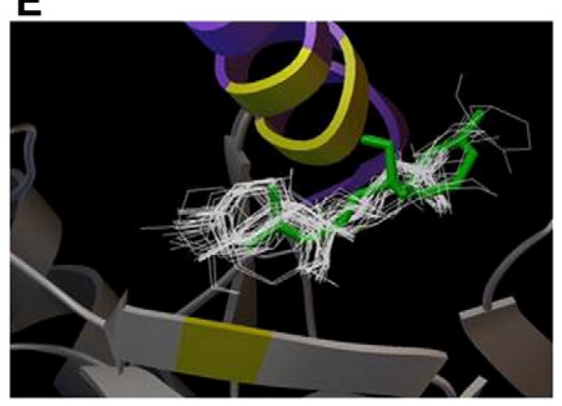

$F$

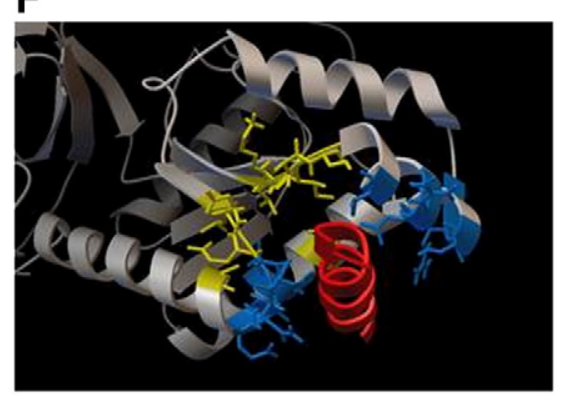

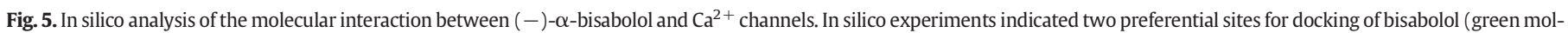

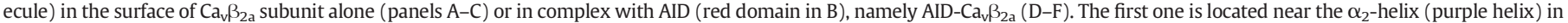

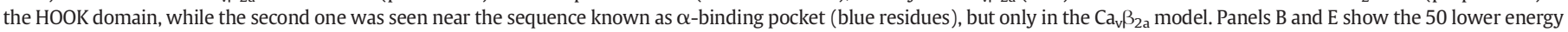

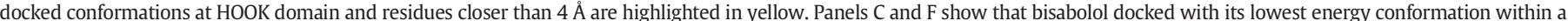

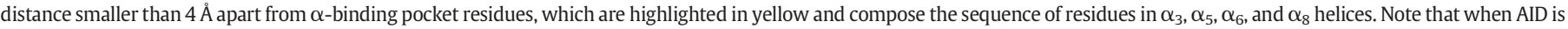
present (F), bisabolol shows no docked conformation in $\alpha$-binding pocket.

indirect influence of VOCC-mediated $\mathrm{Ca}^{2+}$ influx, $(-)-\alpha$-bisabolol was ineffective against the $\mathrm{CaCl}_{2}$-induced contractions in aortic preparations pretreated with phenylephrine under $\mathrm{Ca}^{2+}$-free conditions. These findings do not only reinforce the hypothesis that $(-)$ - $\alpha$-bisabolol acts preferentially upon cellular mechanism that involves inhibition of plasmalemmal $\mathrm{Ca}^{2+}$ influx by VOCCs (electromechanical coupling) in aortic rings but also argues against the idea of a myogenic action as the underlying mechanism by which (-)- $\alpha$-bisabolol induces its vasodilator effect.

In this direction, putative effects of $(-)-\alpha$-bisabolol on contractions induced by intracellular events were therefore investigated herein by studying the four following mechanisms under $\mathrm{Ca}^{2+}$-free conditions. Under such conditions, $(-)$ - $\alpha$-bisabolol did not significantly change (1) the development of transient contraction activated by a phenylephrine-induced stimulus which is expected to result from $\mathrm{Ca}^{2+}$ released from sarcoplasmic reticulum stores upon activation of $\mathrm{IP}_{3}$-sensitive $\mathrm{Ca}^{2+}$ channels [7,20], (2) the caffeine-elicited transient contractions which are expected to result from $\mathrm{Ca}^{2+}$-induced $\mathrm{Ca}^{2+}$ release from the sarcoplasmic reticulum via ryanodine receptors $[11,22]$, (3) the sustained contraction in response to the PKC activator phorbol 12,13-dibutyrate [31,32] which results from cellular events that increase PKC-mediated sensitivity of contractile proteins to intracellular $\mathrm{Ca}^{2+}[24]$, and finally (4) the sustained contractions evoked by exogenous $\mathrm{Ca}^{2+}$ restoration after its internal store depletion with cyclopiazonic acid, an inhibitor of the sarco/endoplasmic reticulum $\mathrm{Ca}^{2+}$-ATPase (SERCA). This exogenous addition of $\mathrm{Ca}^{2+}$ promotes sustained contractions by opening plasmalemmal store-operated $\mathrm{Ca}^{2+}$ channels (SOCCs) [17,19].

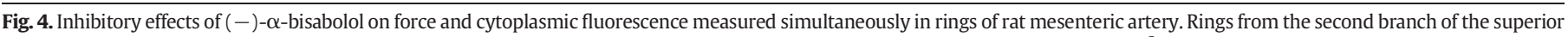

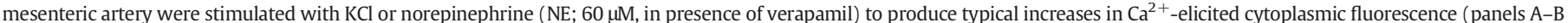

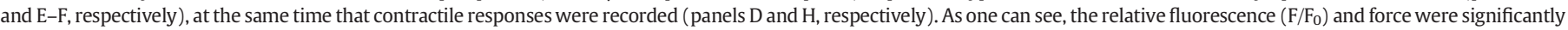

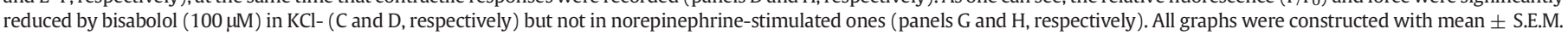
${ }^{*} \mathrm{p}<0.05$, paired Student's t-test ( $\mathrm{n}=4$ preparations for each group). 
It is then reasonable to conclude that the relaxant effects of $(-)-\alpha-$ bisabolol on vascular smooth muscle occur through its inhibitory properties preferentially against contractions mediated by voltagedependent $\mathrm{Ca}^{2+}$ influx. This conclusion is strengthened by the current data obtained during simultaneous measurement of mechanical force and $\left[\mathrm{Ca}^{2+}\right]_{\mathrm{i}}$ in Fluo-4 loaded mesenteric artery rings stimulated with either $\mathrm{KCl}$ or norepinephrine. In fact, our results clearly show that $(-)-\alpha-$ bisabolol at $100 \mu \mathrm{M}$ decreases both the contractile force and the increase in the $\left[\mathrm{Ca}^{2+}\right]_{\mathrm{i}}$ in response to the $\mathrm{KCl}$ stimulus but not in response to norepinephrine. To the best for our knowledge, this is the first study demonstrating that $(-)-\alpha$-bisabolol has the ability to blunt intracellular $\mathrm{Ca}^{2+}$ after a contractile stimulus.

Crystal structures of $C a_{v} \beta_{2 a}$ were employed in the docking experiments of the present study. Found in aortic tissues of rats [9], this $\beta$ subunit is an intracellular auxiliary protein that binds to the poreforming $\alpha 1$ subunit via interaction with ADI, the $\alpha$-interaction domain. $\beta$-Subunit is involved with regulation of channel properties including its voltage-dependent activation [27]. In a first analysis, two docking sites for $(-)$ - $\alpha$-bisabolol were revealed in $\mathrm{Ca}_{\mathrm{v}} \beta_{2 \mathrm{a}}$, one near the HOOK domain, and the other near the $\alpha$-binding pocket. The docking site for $(-)-\alpha$-bisabolol in the HOOK region was located at the $\alpha 2$-helix and concentrated most docked clusters as in $\mathrm{Ca}_{\mathrm{v}} \beta_{2 \mathrm{a}}$ as in AID-Ca $\mathrm{C}_{\mathrm{v}} \mathrm{\beta}_{2 \mathrm{a}}$. Although the HOOK region has been described to exert important regulatory roles allowing interactions of $\mathrm{Ca}_{\mathrm{v}} \beta$ with other proteins such as calmodulin [18], the present in silico analysis could not definitely establish whether the interaction of $(-)$ - $\alpha$-bisabolol with this subunit of voltage-gated $\mathrm{Ca}^{2+}$ channels may result in inhibition of the contractile behavior in live cells.

In contrast, when we adopted the molecular model $\mathrm{Ca}_{\mathrm{v}} \beta_{2 \mathrm{a}}$ in complex with the $\alpha$-interaction domain ( $\mathrm{AID}-\mathrm{Ca}_{\mathrm{v}} \beta_{2 \mathrm{a}}$ ), only one docking site was seen probably in virtue of the spatial impairment imposed by AID in the present in silico approaching of $(-)-\alpha-$ bisabolol with the $C a_{v} \beta_{2 a} \alpha$-binding pocket. Such finding appears of importance as this region is involved with the engagement between $C a_{v} \beta_{2 a}$ and AID, a peptide consisting of 18 residues found in all Cav1 L-type pore-forming $\alpha 1$ subunit [1]. As previous studies established that the interaction between $\alpha$ and $\beta$ subunits of the voltagedependent $\mathrm{Ca}^{2+}$ channels is reversible even in intact cells $[1,8]$, it is reasonable to postulate that $(-)$ - $\alpha$-bisabolol may produce its vasodilator effects through its putative ability to uncouple $\mathrm{Ca}_{\mathrm{v}} \beta_{2 \mathrm{a}}$ from AID. It is well-known that co-expression of $\alpha 1$ and $\beta$ subunits may improve $\mathrm{Ca}^{2+}$ channel currents, although $\beta$ subunits could not interfere directly with ion permeation through the channel [1]. Notwithstanding, considering that the direct blockade of the $\mathrm{Ca}^{2+}$ channel could not be discarded, if an inhibitory action can be confirmed as result of such molecular interaction between $(-)$ - $\alpha$-bisabolol and $\mathrm{Ca}_{\mathrm{v}} \beta_{2 \mathrm{a}}$, then its vasodilator effects may likely be derived from an allosteric influence of $(-)$ - $\alpha$-bisabolol on $\mathrm{Ca}_{\mathrm{v}} \beta_{2 \mathrm{a}}$ rather than from a direct blocking action on $\mathrm{Ca}^{2+}$ channel pore in $\alpha 1$ subunit.

In conclusion, our findings indicate that $(-)-\alpha$-bisabolol had concentration-dependent vasorelaxant effects which were independent of the involvement of nitric oxide and prostaglandin release as well as ATP-sensitive $\mathrm{K}^{+}$channels, sGC or adenylyl cyclase activation. Rather, the present confocal imaging and in silico analysis of data reinforce the hypothesis that $(-)-\alpha$-bisabolol interfere preferentially with contractile responses evoked by $\mathrm{Ca}^{2+}$ influx through voltage-dependent $\mathrm{Ca}^{2+}$ channels.

\section{Acknowledgments}

We are indebted with Dr. Jairo Diniz Filho for his help with docking experiments. This work was supported by the "Conselho Nacional de Desenvolvimento Científico e Tecnológico (CNPq) (Edital INCT573928/ 2008-8)" through the "Instituto Nacional de Biomedicina do Semiárido Brasileiro (INCT-IBISAB)" and the "Programa Nacional de PósDoutorado" from the "Coordenação de Aperfeiçoamento de Pessoal de
Nível Superior (CAPES) (PNPD 2536/2011) and CNPq". This manuscript is part of a $\mathrm{PhD}$ thesis developed by RJB de Siqueira.

\section{References}

[1] Buraei Z, Yang J. The $\beta$ subunit of voltage-gated $\mathrm{Ca}^{2+}$ channels. Physiol Rev 2010;90: 1461-506.

[2] Cavalieri E, Mariotto S, Fabrizi C, Carcereri A, Gottardo R, Leone S, Berra LV, Lauro GM, Ciampa AR, Suzuki H. $\alpha$-Bisabolol, a nontoxic natural compound, strongly induces apoptosis in glioma cells. Biochem Biophys Res Commun 2004:315:589-94.

[3] Chen W, Hou J, Yin Y, Jang J, Zheng Z, Fan H, Zou G. $\alpha$-Bisabolol induces dose- and time-dependent apoptosis in HepG2 cells via a Fas- and mitochondrial-related pathway, involves p53 and NFkB. Biochem Pharmacol 2010;80:247-54.

[4] Darra E, Abdel-Azeimb S, Manara A, Shoji K, Marechal JD, Mariotto S, Cavalieri E Perbellini L, Pizza C, Perahia D, Crimi M, Suzuki H. Insight into the apoptosisinducing action of alpha-bisabolol towards malignant tumor cells: involvement of lipid rafts and bid. Arch Biochem Biophys 2008;476:113-23.

[5] de Siqueira RJB, Freire WBS, Vasconcelos-Silva AA, Fonseca-Magalhães PA, Lima FJB, Brito TS, Mourão LTC, Ribeiro RA, Lahlou S, Magalhães PJC. In-vitro characterization of the pharmacological effects induced by $(-)-\alpha$-bisabolol in rat smooth muscle preparations. Can J Physiol Pharmacol 2012;90:23-35.

[6] Hanwell MD, Curtis DE, Lonie DC, Vandermeersch T, Zurek E, Hutchison GR. Avogadro: an advanced semantic chemical editor, visualization, and analysis platform. J Cheminform 2012;4:17.

[7] Hashimoto T, Hirata M, Itoh T, Kanmura Y, Kuriyama H. Inositol 1,4,5-trisphosphate activates pharmacomechanical coupling in smooth muscle of the rabbit mesenteric artery. J Physiol 1986;370:605-18.

[8] Hohaus A, Poteser M, Romanin C, Klugbauer N, Hofmann F, Morano I, Haase H, Groschner K. Modulation of the smooth-muscle L-type $\mathrm{Ca}^{2+}$ channel alpha1 subunit (alpha1C-b) by the beta2a subunit: a peptide which inhibits binding of beta to the III linker of alpha1 induces functional uncoupling. Biochem J 2000;15:657-65.

[9] Hullin R, SingerLahat D, Freichel M, Biel M, Dascal N, Hofmann F, Flockerzi V. Calcium channel $\beta$ subunit heterogeneity: functional expression of cloned cDNA from heart, aorta and brain. EMBO J 1992;11:885-90.

[10] Kamatou GPP, Viljoen AM. A review of the application and pharmacological properties of $\alpha$-bisabolol and $\alpha$-bisabolol-rich oils. J Am Oil Chem Soc 2010;87:1-7.

[11] Karaki H, Weiss GB. Calcium release in smooth muscle. Life Sci 1988;44:111-22.

[12] Khayyal MT, el-Ghazaly MA, Kenawy SA, Seif-el-Nasr M, Mahran LG, Kafafi YA, Okpanyi SN. Antiulcerogenic effect of some gastrointestinally acting plant extracts and their combination. Arzneimittelforschung 2001;51:545-53.

[13] Menezes IA, Barreto CM, Antoniolli AR, Santos MR, de Sousa DP. Hypotensive activity of terpenes found in essential oils. Z Naturforsch C 2010;65:562-6.

[14] Morris GM, Huey R, Lindstrom W, Sanner MF, Belew RK, Goodsell DS, Olson AJ. AutoDock4 and AutoDockTools4: automated docking with selective receptor flexibility. J Comput Chem 2009;16:2785-91.

[15] Murray RK, Kotlikoff MI. Receptor-activated calcium influx in human airway smooth muscle cells. J Physiol 1991;435:123-44.

[16] Neuhaus-Carlisle K, Vierling W, Wagner H. Screening of plant extracts and plant constituents for calcium-channel blocking activity. Phytomedicine 1997:4:67-71.

[17] Noguera MA, D'Ocon MP. Evidence that depletion of internal calcium stores sensitive to noradrenaline elicits a contractile response dependent on extracellular calcium in rat aorta. 1993;110:861-7.

[18] Paarmann I, Spangenberg O, Lavie A, Konrad M. Formation of complexes between $\mathrm{Ca}^{2+}$-calmodulin and the synapse-associated protein SAP97 requires the SH3 domain-guanylate kinase domain-connecting HOOK region. J Biol Chem 2002;25: 40832-8.

[19] Putney Jr JW, McKay RR. Capacitative calcium entry channels. Bioessays 1999;21: 38-46.

[20] Rembold CM. Regulation of contraction and relaxation in arterial smooth muscle Hypertension 1992;20:129-37.

[21] Roberts RE, Allen S, Chang AP, Henderson H, Hobson GC, Karania B, Morgan KN, Pek AS, Raghvani K, Shee CY, Shikotra J, Street E, Abbas Z, Ellis K, Heer JK, Alexander SP. Distinct mechanisms of relaxation to bioactive components from chamomile species in porcine isolated blood vessels. Toxicol Appl Pharmacol 2013;272:797-805.

[22] Sato K, Ozaki H, Karaki H. Multiple effects of caffeine on contraction and cytosolic free $\mathrm{Ca}^{2+}$ levels in vascular smooth muscle of rat aorta. Naunyn Schmiedebergs Arch Pharmacol 1988;338:443-8.

[23] Saito K, Kitajima T, Uchida K, Kamikawa Y. Effects of $\mathrm{Ba}^{2+}$ on norepinephrineinduced contraction of rat thoracic aorta in vitro. Pharmacology 2000;61:1-5.

[24] Somlyo AP, Somlyo AV. $\mathrm{Ca}^{2+}$ sensitivity of smooth muscle and nonmuscle myosin II: modulated by G proteins, kinases, and myosin phosphatase. Physiol Rev 2003;83: 1258-325.

[25] Somlyo AV, Somlyo AP. Electromechanical and pharmacomechanical coupling in vascular smooth muscle. J Pharmacol Exp Ther 1968;159:129-45.

[26] Torrado S, Agis A, Jimenez ME, Cadorniga R. Effect of dissolution profile and (-)alpha-bisabolol on the gastrotoxicity of acetylsalicylic acid. Pharmazie 1995;50(2): 141-3.

[27] Van Petegem F, Clark KA, Chatelain FC, Minor Jr DL. Structure of a complex between a voltage-gated calcium channel beta-subunit and an alpha-subunit domain. Nature 2004;429:671-5.

[28] Vuorela H, Vuorela P, Tornquist K, Alaranta S. Calcium channel blocking activity: screening methods for plant derived compounds. Phytomedicine 1997;4:167-80.

[29] Zhong H, Minneman KP. Alpha1-adrenoceptor subtypes. Eur J Pharmacol 1999;375: 261-76. 
[30] Zygmunt PM, Larsson B, Sterner O, Vinge E, Högestätt ED. Calcium antagonistic properties of the sesquiterpene T-cadinol and related substances: structure-activity studies. Pharmacol Toxicol 1993;73:3-9.

[31] Yanagita T, Kobayashi H, Yamamoto R, Takami Y, Yokoo H, Yuhi T, Nakayama T, Wada A. Protein kinase $C$ and the opposite regulation of sodium channel alpha- and beta1-subunit mRNA levels in adrenal chromaffin cells. J Neurochem 1999;73: 1749-57.

[32] Walsh MP, Horowitz A, Clément-Chomienne O, Andrea JE, Allen BG, Morgan KG. Protein kinase $\mathrm{C}$ mediation of $\mathrm{Ca}(2+)$-independent contractions of vascular smooth muscle. Biochem Cell Biol 1996;74:485-502. 